\title{
Justicia como imparcialidad dialógica. Una perspectiva de la justicia imparcial compatible con las demandas de los grupos desfavorecidos.
}

\author{
Towards a dialogical approach of justice as fairness. \\ A perspective of impartial justice compatible with the \\ demands of disadvantaged groups.
}

IVÁN TEIMIL GARCíA

Universidad de Oviedo

\begin{abstract}
RESUMEN. Los críticos de las teorías liberales de la justicia han denunciado que ciertas suposiciones de tales teorías como la imparcialidad y el universalismo no son realistas y además envuelven perniciosos fines ideológicos. Contra esta perspectiva, sostengo que solo una concepción de la justicia imparcialista y universalista, basada en una visión deliberativa de la política y de la participación, puede incluir de manera coherente las demandas de las minorías en el modelo democrático que proponga. Entiendo esta imparcialidad como imparcialidad deliberativadialógica. En este ensayo defiendo que imparcialidad, universalismo y diferencia, lejos de ejemplificar una unión anómala o contradictoria, forman una constelación de elementos inseparables que dan sentido a una perspectiva completa y rigurosa de la justicia.
\end{abstract}

Palabras clave: justicia, imparcialidad dialógica, dominación y opresión, diferencia, universalismo, grupos desaventajados, inclusión.

\section{Introducción}

Uno de los retos fundamentales ante los que se enfrentó la filosofía política del
AbStRact. The critics of the liberal theories of justice have denounce that basic assumptions of these theories such as impartiality and universalism are not realistic and involve pernicious ideological aims. Against this perspective, I sustain that only an impartial and universalistic conception of justice, based on a deliberative vision of politics and participation, could add consistently the demands of the minorities in its democratic model, and at the same time put that model on practice. I understand this impartiality in a deliberativedialogical way. In this essay I defend that impartiality, universalism and difference far from exemplify an anomalous union, make a constellation of inseparable elements, constellation that gives the sense to a truly inclusive and rigorous perspective of justice.

Key words: justice, dialogical impartiality, domination and oppression, difference, universalism, disadvantaged groups, inclusion.

siglo xx es el de acomodar las exigencias legítimas que los grupos desfavorecidos de la sociedad plantean a nuestro sistema democrático. Gran parte de las teorías 
políticas de la justicia y la democracia del pasado siglo han hecho explícito que las bases de tal sistema deben erigirse sobre fundamentos imparciales y escrupulosamente respetuosos con las libertades y derechos de todos los ciudadanos, consolidados en nuestra cultura públicopolítica. En contraste, según los teóricos que han hablado de medidas específicas para corregir la situación de desventaja de los grupos desfavorecidos de la sociedad, la teoría política no debería construirse sobre los parámetros imparcialistas y universalistas que han manejado el liberalismo e incluso cierto sector del republicanismo. ${ }^{1}$ Para estos autores, lo primordial es la consideración de la diferencia y la constatación de la opresión real que sufren ciertas identidades desvalorizadas, aún en las sociedades democráticamente más avanzadas. El compaginar la atención y las medidas necesarias para paliar la injusta y arbitraria situación a la que se ven sometidas las personas que integran sectores minoritarios o desfavorecidos de la sociedad, con los derechos formales más fundamentales, sigue siendo una de las tareas pendientes en nuestro presente democrático, máxime cuando algunas de las reivindicaciones de estos grupos alcanzan ahora un carácter transnacional.

Por lo mismo, se vuelve perentorio el diseño de programas y políticas que dispongan una convivencia más democrática y plural en el futuro. Con este objetivo en mente, sostendré que la justicia como imparcialidad no es contrapuesta sino, al contrario, complementaria de la justicia como atención a la diferencia, e intentaré pergeñar un modo igualmente congruente de compaginar ambos tipos de teorías políticas señalando sus puntos de aproximación. Para llevar a cabo este cometido analizaré la interpretación de una de las teóricas de la diferencia más relevantes de los últimos decenios, Iris Marion Young. ${ }^{2}$ Haré referencia a esas ideas y presupuestos filosófico-políticos que según la autora son responsables de un olvido de los grupos desfavorecidos de la sociedad así como perpetuadores de la opresión a la que tales grupos se ven sometidos (II). En el apartado siguiente, explicaré por qué considero injustificado el rechazo por parte de Young de una cierta idea de imparcialidad, y por qué resulta contradictorio este rechazo con su aceptación de los supuestos centrales del deliberativismo y la ética discursiva (III). A continuación rebatiré los argumentos de Young contra el universalismo, sirviéndome de las ideas de Sheyla Benhabib (IV) y concluiré que tanto imparcialidad dialógica como universalismo débil o interactivo son elementos imprescindibles de una concepción ético-política de la justicia aceptable (V)

\section{La dominación y la opresión como puntos de partida de la teoría de la justicia}

Iris Marion Young declara en las primeras páginas de su obra La justicia y la política de la diferencia que una teoría de la justicia debe comenzar por los conceptos de dominación y opresión. Según esta autora, las reflexiones tradicionales se erigen como constructos blindados y atemporales válidos para todos los tiempos y mundos posibles. Rechazar esta teoría tradicional no implica para Young renunciar al discurso racional sobre la justicia. Realizar una reflexión social y temporalmente contextualizada sobre la justicia no nos compromete sin más con lo fáctico, de lo cual ha de hacerse una evaluación normativa. Pero ha de tenerse en cuenta que estas reflexiones surgen, como expresa la autora "de oír un grito de sufrimiento o angustia, o de sentirse angustiada una misma». ${ }^{3}$ 
A juicio de Young, la deficiencia fundamental de las teorías tradicionales es su restricción del significado de justicia social a la distribución moralmente correcta de beneficios y cargas. Por un lado, este análisis se centra en la asignación de bienes materiales, tales como cosas, recursos, ingresos y riqueza, posiciones sociales y laborales. En consecuencia, la teoría de la justicia (especialmente la de cuño liberal o liberal igualitarista) ignora, la estructura social y el contexto institucional que determinan los modelos de distribución, dando automáticamente por buenos tales modelos. Por otro lado, la ampliación metafórica del concepto de distribución a bienes no materiales como el poder, los derechos, las oportunidades o la autoestima (al modo de Rawls) tiene como consecuencia la representación de estos bienes como entidades estáticas, cosifica las relaciones sociales y las reglas institucionales y subsume en modelos harto abstractos la complejidad de los procesos sociales.

Para Young, no es correcto entender justicia social y distribución como conceptos co-extensivos. ${ }^{4}$ El paradigma distributivo asumido sin restricciones erige el bienestar individual como principio supremo y fomenta, por tanto, un atomismo social y un modelo estático de sociedad, además de ocultar las deficiencias de base del propio sistema institucional. En palabras de Young:

El paradigma distributivo tiende a concebir a los individuos como átomos sociales, lógicamente anteriores a las relaciones e instituciones sociales. (...) Una concepción atomista de este tipo que concibe a los individuos como una sustancia a la que se adhieren atributos no llega a percibir que las identidades y capacidades individuales son ellas mismas, en muchos sentidos, producto de procesos y relaciones sociales. Las sociedades no distribuyen simplemente bienes entre personas que son lo que son con independencia de la sociedad, sino que forman a los individuos en sus identidades y capacidades. Sin embargo, la lógica distributiva no deja lugar para concebir la capacidad o incapacidad de las personas como una función de las relaciones entre ellas. ${ }^{5}$

Por ende, el paradigma distributivo de la justicia oculta, las otras formas de injusticia, muchas veces unidas a injusticias distributivas, pero no todas ellas potencialmente reductibles a problemas de distribución. Por ejemplo, la división sexual del trabajo, la discriminación de los inmigrantes o personas de raza no blanca, ya sea ésta abierta o implícita, la homofobia, el heterosexismo, la imposición de un modelo familiar o de una forma mayoritaria de vida o el desprecio hacia las personas mayores o disminuidas físicas o psíquicas.

Según Young, la teoría de la justicia debería limitar explícitamente el concepto de distribución a bienes materiales tales como las posesiones, los recursos naturales o el dinero. La justicia comporta, en cambio, una extensión mucho mayor como concepto ético-político que hace responsable de la buena marcha de la empresa social a la sociedad en su conjunto. Con la teoría liberal Young coincidiría en que la justicia se refiere a las condiciones institucionales y no a las preferencias particulares y formas de vida de los grupos. Ahora bien, según esta autora, existen dos valores universalistas comprendidos en todo proyecto de vida buena cuya violación nos introduce de lleno en las cuestiones de justicia: el primero, desarrollar y ejercer nuestras capacidades y expresar nuestra experiencia; el segundo, participar en la determinación de nuestra acción y de las condiciones de nuestra acción. A estos dos valores sociales les corresponden dos condiciones que definen la injusticia: la opresión, que resulta de las trabas institucionales al autodesarrollo; y la domi- 
nación, consecuencia de los impedimentos institucionales a la autodeterminación. En definitiva, justicia y vida buena mantienen su relación de no-identidad, si bien es objeto de la justicia social el grado en que las condiciones institucionales suscritas por la sociedad permiten el desarrollo y la realización de estos valores universalistas de la vida buena:

La justicia no es idéntica a la vida buena como tal. Se puede decir, en cambio, que concierne a la justicia social el grado en que la sociedad contiene y sustenta las condiciones institucionales necesarias para la realización de estos valores. ${ }^{6}$

La insistencia de algunos teóricos en circunscribir los problemas de justicia a problemas distributivos refuerza, en opinión de Young, uno de los factores más relevantes que influyen en la opresión y la dominación: la despolitización y el retroceso de la participación activa en la vida pública por parte de los ciudadanos. En este sentido, las teorías que no evalúan las estructuras institucionales que determinan el contexto y las condiciones distributivas, eluden la crítica a las relaciones de poder y a la cultura dominante en la sociedad de bienestar. En palabras de Young: "A través de la orientación al bienestar se construyen personas que son ciudadanas del mismo modo en que son clientes o consumidoras». ${ }^{7}$ En el atomista espacio de egoístas racionales que este panorama prefigura apenas queda lugar para las reivindicaciones que se aparten de la ideología de uso común. Por el contrario, los derechos y procedimientos formalmente establecidos en los cauces democráticos, tienen sólo pleno sentido si los grupos oprimidos poseen la capacidad de expresar en el ámbito público sus intereses y experiencias.

En opinión de nuestra autora, la idea central a la base de las teorías de la justicia distributivas es la imparcialidad, que busca reducir las diferencias a una lógica de la identidad, a través de la consagración de un sistema de derechos individuales, y de la neutralidad escrupulosa ante las diferentes formas de vida ética. Sin embargo, a juicio de Young, esta imparcialidad sólo se consigue mediante el distanciamiento con respecto a los sentimientos, filiaciones y particularidades que configuran la vida de las personas, elementos que por el contrario, siguen inevitablemente actuando y construyendo la vida social en los contextos reales. ${ }^{8}$ "El ideal de imparcialidad en la teoría moral expresa una lógica de la identidad que busca reducir las diferencias a una unidad». ${ }^{9}$ Por lo tanto, la imparcialidad para Young, además de una impostura de la teoría política, resulta ser un ideal irrealizable, dado que las citadas particularidades no pueden ni deben ser retiradas del conjunto de elementos plurales que estructuran la sociedad. El ideal de imparcialidad persigue, según esta autora, fines ideológicos, eludiendo, en suma, la tarea de habérselas con la pluralidad ingente de formas de vida éticas y los mecanismos mediante los cuales éstas arriban a los consensos sociales básicos para la convivencia.

En definitiva, desde la perspectiva de Young, la imparcialidad no sólo es inviable en la práctica sino que trae consigo consecuencias adversas:

El extendido compromiso con el ideal de imparcialidad es útil para al menos tres funciones ideológicas. Sustenta la idea del estado neutral, que a su vez sirve en parte de fundamento al paradigma distributivo de justicia. Legitima la autoridad burocrática, así como los procesos jerárquicos de toma de decisiones democráticamente tomadas. Y por último, refuerza la opresión al transformar el punto de vista de los grupos privilegiados en una posición universal. Sostengo que, en lugar de la imparcialidad deberíamos buscar la equidad social en un contexto de heterogeneidad y discurso parcial. ${ }^{10}$ 
Para instaurar esta nueva dinámica social se requiere, de una auténtica revolución cultural que persiga subvertir los prejuicios, estereotipos y hábitos inconscientes que siguen identificando a homosexuales, mujeres, inmigrantes o personas discapacitadas y de edad avanzada como individuos repulsivos, peligrosos o amenazadores de la identidad generalizada. En opinión de Young, una política de la diferencia debe, por lo tanto, otorgar voz a los grupos desfavorecidos de la sociedad, cuyas demandas han sido «desvalorizadas o excluidas por la política tradicional», la cual asume un significado esencialista y estigmatizador de la diferencia.

A juicio de Young, el pluralismo democrático, no exige solamente un sistema de derechos presidido por la imparcialidad, sino de un entramado dual de derechos compuesto por los derechos cívicos y políticos generales de participación e inclusión y un conjunto de políticas y derechos específicos y con conciencia de grupo. En algunos casos resultaría necesario que los colectivos alcanzasen incluso representación parlamentaria, la cual garantizaría mayor equidad procesal a la hora de determinar la agenda institucional, y promovería la atención a las demandas de todas las personas y no de sólo aquellas que se encuentran en posiciones sociales o económicas privilegiadas. Pero además, según Young, el derecho a la participación y a la representación grupal tiene un efecto emancipador y sugestivo, en tanto que el acceso de los grupos despreciados al ámbito público, obligaría a los privilegiados a entrar en el juego deliberativo y, al menos, prestar oídos a aquellos cuyos reclamos permanecían silenciados. El espacio público democrático no es un paraíso de completo entendimiento ni una unidad trascendedora de la diferencia grupal pero sí un lugar en que cada grupo social reconoce a los demás y está dispuesto a escucharlos, un lugar, «en el que la gente observa y aprecia diversas manifestaciones culturales que no comparte y que no entiende acabadamente». ${ }^{11}$

\section{El error de Young: el olvido de la «imparcialidad dialógica»}

Young está de acuerdo con los presupuestos de la ética comunicativa de Habermas, aunque afirma que éste mantiene un compromiso implícito con un espacio público homogéneo. Incluso dice aceptar la idea de justicia que pone en circulación esta ética comunicativa, la cual se aparta de la pura distribución de recursos para centrarse en las cuestiones procedimentales de participación en la deliberación y toma de decisiones. Sin embargo, Young olvida una de las notas fundamentales de la justicia tal como es concebida en la teoría habermasiana. La imparcialidad, uno de los supuestos más denostados por Young, para esta autora sospechoso de justificar la exclusión de las diferencias grupales que practican las políticas liberales, constituye una de las pautas más relevantes de la ética comunicativa y la más esencial de la concepción de la justicia que le viene aneja. Recordemos cómo se expresa esta idea en Verdad y justificación:

Cuanto más avanza la erosión de las ideas de justicia heredadas, más se va depurando la idea de «justicia» hasta convertirse en un concepto procedimental, aunque no menos exigente. La expectativa de legitimidad — según la cual sólo pueden merecer reconocimiento aquellas normas que «son buenas para todos en la misma medida»- se puede satisfacer hoy solamente con la ayuda de un procedimiento que, bajo condiciones de inclusión de todos los potencialmente afectados, asegure la imparcialidad en el sentido de atender en la misma medida todos los intereses implicados. ${ }^{12}$ 
Young está en lo correcto cuando entiende la justicia de la ética comunicativa como un concepto procedimental. Sin embargo, a lo largo de su obra desliza de manera reiterada un error conceptual en relación a este concepto: no sólo obvia la definición de justicia postradicional tal como Habermas la entiende - como «imparcialidad de la formación del juicio»— sino que además promueve un modelo democrático que exige una definición de la justicia de este tipo, mientras rechaza explícitamente tal definición. Por lo mismo, la asunción de Young de una ética comunicativa y de un concepto de justicia postradicional y procedimental es absolutamente incompatible con el rechazo de la idea de imparcialidad.

Así pues, por un lado, es preciso aclarar a qué tipo de concepción de la imparcialidad está aludiendo la autora en sus críticas. Por otro lado, se debe examinar si su rechazo frontal de esta noción fundamental para la teorías de la justicia de corte universalista no contradice sus propios presupuestos y una de sus propuestas generales: la de entender el espacio público-político como un ámbito heterogéneo y plural de participación ciudadana en el que han de hallar cabida todas las voces y reivindicaciones, siempre y cuando respeten los principios básicos de convivencia democrática.

En lo que al primer aspecto se refiere, es necesario especificar que Young parece dirigir sus críticas a las teorías imparcialistas de corte liberal igualitarista, entre cuyos representantes eminentes están J. Rawls, R. Dworkin o B. Ackerman. ${ }^{13}$ Todos ellos circunscriben el concepto de imparcialidad al ámbito de las instituciones políticas, encargadas de salvaguardar los derechos fundamentales de los individuos. Estos se entienden como «esencias constitucionales» o «cartas de triunfo» de nuestra cultura democrática, como aquellos logros fundamentales e insoslayables desde los cuales no cabe retroceso alguno. La imparcialidad representa en este caso la garantía de que el estado liberal vela por los derechos fundamentales que representan el consenso más amplio y profundo que han logrado alcanzar los ciudadanos de una sociedad determinada. Sin embargo, Young no repara en la idea de imparcialidad manejada por republicanos e incluso liberales de corte deliberativista. Para todos ellos la democracia comporta un sentido epistémico, esto es, una capacidad de autocorrección y revisión a través de la transformación de las preferencias endógenas de los implicados en un problema de justicia. Esta transformación ha de darse, si la sociedad marcha hacia la democratización y la participación abierta y plural, tanto en el ámbito de las instituciones representativas como en el ámbito de las deliberaciones sociales informales. En este sentido la imparcialidad se expresa en lo que Habermas describe como presupuestos básicos de la comunicación orientada al entendimiento, y los deliberativistas definen como requisitos fundamentales para una deliberación inclusiva y plural, a saber, la inclusión de todas las voces relevantes, la igualdad de participación y la posibilidad de determinación de la agenda política, la reciprocidad, la simetría de todos los participantes y la apertura del espacio deliberativo a los grupos tradicionalmente desfavorecidos.

La justicia como imparcialidad, se refiere entonces a los procesos de toma de decisiones y no sólo a los petrificados aunque insoslayables sistemas de derechos, más a la acción y a la autonomía de sujetos que pueden organizadamente alzar su voz contra la injusticia que a la labor de unas instituciones situadas por encima de quienes eligen a sus represen- 
tantes. En expresión común, la imparcialidad se refiere a «calzarse los zapatos del otro» sin eludir la responsabilidad de admitir las reclamaciones de quienes padecen desventajas y siendo igualmente conscientes de los límites democráticos a tales reclamaciones. La justicia como imparcialidad, entendida de este modo discursivo-deliberativo no es contraria a la política de la diferencia, antes bien es necesaria como parámetro procedimental básico del discurso democrático. En lugar de reforzar los prejuicios al servicio de la ideología mayoritaria, tal como opina Young, exige la puesta en común de todos los puntos de vista y la discusión pública sobre cuáles son los intereses que merecen legítimo reconocimiento. En definitiva, la imparcialidad obliga a la toma en consideración de la diferencia, debido a que su mecanismo no es la simple universalización, sino la decentración de la perspectiva individual y grupal y la disposición al examen deliberativo de las perspectivas ajenas.

El error de Young consiste en no haber reparado en que la idea postradicional de justicia que funciona como pauta procedimental en la ética comunicativa y la concepción deliberativa de la democracia es la imparcialidad. La decentración de la perspectiva propia y la disposición a iniciar una competencia argumentativa — «dando el brazo a torcer» si los adversarios cuentan con mejores razones para justificar su posturaes lo que define la imparcialidad de la formación del juicio. Un escenario en que nuestro entramado moral y político se concibe como susceptible de transformación y reconstrucción intersubjetiva. Teniendo en cuenta esta explicación no veo como Young podría coherentemente rechazar la imparcialidad, más aún cuando, siguiendo a Habermas, ella misma reproduce una explicación de la justicia parecida a la anterior:
La fundamentación de esta afirmación, está en la concepción de Habermas respecto de la ética comunicativa. En ausencia del reyfilósofo con acceso a las verdades normativas trascendentes, la única base para sostener que una política o una decisión es justa consiste en que dicha política o decisión haya sido tomada en un ámbito público que a su vez haya propiciado verdaderamente la libre expresión de todas las necesidades y puntos de vista.(...) Con una participación tal la gente logrará convencer a las demás personas idealmente - sólo si formula sus propuestas como apelaciones a la justicia, dado que otras personas les pedirán que den cuenta de tales propuestas si creen que sus propios intereses están en peligro. (...) Es así como el proceso democrático de toma de decisiones tiende a promover resultados justos, porque hay más posibilidades de introducir criterios de justicia en este tipo de procesos de toma de decisiones, y porque se maximiza el conocimiento y perspectivas sociales que contribuyen a pensar acerca de la política. ${ }^{14}$

\section{Una crítica al antiuniversalismo de Young}

Considero igualmente que Young no debería rechazar un universalismo normativo débil tal como lo entienden las concepciones deliberativistas de la democracia y la misma ética discursiva. El modelo político de relaciones sociales de diferencia sin exclusión que propone Young, se articula a través de una concepción de la sociedad en que las personas aceptan e intentan comprender otras perspectivas a través de la interacción y la comunicación. En esta interacción se da una ampliación de las perspectivas cognoscitivas de los participantes, esto es, se inicia una competencia argumentativa para establecer cuáles son las medidas o normas que merecen asentimiento generalizado o, utilizando una expresión de Tim Scanlon, cuáles de estas normas o medidas están respaldadas por razones que nadie podría razonablemente recha- 
zar. ${ }^{15}$ La generalización opera igualmente en el nivel argumentativo de los grupos sociales que buscarán establecer una postura común dentro de la heterogeneidad que caracteriza a los propios colectivos. Estos colectivos elevarán sus puntos de vista con el fin de ser escuchados por las instituciones y la sociedad en su conjunto. A veces, en un nuevo esfuerzo de generalización su influencia o impacto propiciará el desarrollo de nuevas leyes y una mayor sensibilidad social hacia los temas y reivindicaciones que dichos grupos han traído a la esfera pública.

La comprensión de la esfera pública como un lugar en que es posible la generalización de argumentos, llegando incluso a ocasionar cambios en el derecho positivo necesita de un universalismo normativo. Young rechaza explícitamente las teorías contextualistas y comunitaristas por su tendencia a establecer como válido un único ideal de vida. Sin embargo, al criticar el universalismo de corte liberal Young cierra las puertas a todo universalismo. Nuevamente olvida que una concepción de la esfera pública acorde con la ética discursiva lo presupone. En opinión de los cognitivistas morales, siempre que estamos dispuestos a argumentar para llegar a un acuerdo sobre las diferentes perspectivas en liza, presuponemos una operación universalizadora. Nadie racional iniciaría la comunicación con miras al entendimiento si no adosara una pretensión de validez universal - ya sea de verdad, de rectitud normativa o de veracidad expresiva- a su discurso. La propia noción de pretensión de validez expresa el supuesto de incondicionalidad del habla orientada al entendimiento. Si no formuláramos esta pretensión implícita en nuestros juicios no iniciaríamos nunca ningún proceso comunicativo. En este sentido, podemos decir que un espacio público con buena salud democrática es el lugar idóneo para el desempeño de pretensiones de validez, y este desempeño lleva igualmente aparejado un ejercicio de universalización en tanto que lo buscado es determinar lo que está en el interés de todos. Sólo un universalismo no ingenuo y consciente de la particularidad puede llevarnos a un reconocimiento de las pretensiones de validez integradas en las reivindicaciones de los grupos sociales. ¿Cómo sino podríamos decentrar nuestra propia perspectiva egocéntrica para al menos considerar críticamente la perspectiva de los demás? Las pretensiones de validez remiten a la reversibilidad de la argumentación sobre normas: en tanto que pretensiones o aspiraciones no son válidas «per se» sino que deben ser fundamentadas y pueden ser revisadas e incluso retiradas ante la mayor fortaleza de otros argumentos. ${ }^{16}$

Para ahondar en mi crítica a las incongruencias de la concepción de la justicia de Young y en mi defensa del universalismo utilizaré la argumentación que en su favor lleva a cabo Sheyla Benhabib. A juicio de Benhabib, el universalismo moral y político que nos lega la modernidad (con sus ideales de justicia, respeto universal, autonomía, libertades políticas y civiles) sigue siendo necesario, a pesar de estar necesitado de reformulación. Una reconstrucción del universalismo pasa por el rechazo de un concepto sustancialista de racionalidad y la defensa de otro de carácter discursivocomunicativo. Por ende, este universalismo nos exige reconocer que los sujetos de la razón son criaturas finitas, corpóreas y concretas y no entidades abstractas o trascendentales. Los elementos fundamentales de un «universalismo interactivo» son según Benhabib los siguientes:

La reformulación pragmática universal de la base de convalidación de afirmaciones de verdad en términos de una teoría discursiva 
de la justificación; la visión de un ser humano corporeizado e incrustado cuya identidad se constituye de modo narrativo, y la reformulación del punto de vista moral como el logro contingente de una forma interactiva de racionalidad y no como el punto de vista intemporal de una razón legislativa. ${ }^{17}$

Benhabib trae a colación el dilema que se cierne sobre los presupuestos básicos de un punto de vista moral así concebido. Por un lado, los presupuestos comunicativos universales y necesarios del habla argumentativa son definidos con tal brevedad y formalismo en la teoría de Habermas que resultan aparentemente triviales. Por otro lado, si no los consideramos triviales entonces hay que suponer que estos presupuestos incluyen premisas sustantivas más polémicas que no guardan coherencia con la idea de servir como condiciones mínimas, y por lo tanto, contradicen el propósito inicial de tales presupuestos. El propio Habermas reconoce que las condiciones formales de los discursos válidos poseen, pese a su abstracción, contenido ético. Para Benhabib, estas normas incluyen evidentes supuestos éticos que podríamos agrupar bajo dos rótulos. Primero, los presupuestos exigen que reconozcamos el derecho de todos los seres capaces de lenguaje y acción a participar en la argumentación moral, lo cual es lo mismo que referirse a un «principio de respeto moral universal». Segundo, estas condiciones establecen que dentro de tales discursos morales, todos los participantes tienen los mismos y simétricos derechos de iniciar nuevos temas, pedir reflexión sobre los presupuestos de la conversación, etc., todo lo cual constituye para Benhabib un «principio de reciprocidad igualitaria». ${ }^{18}$

El hecho de que las presuposiciones formales de los discursos prácticos encierren premisas éticas que las aparta de la trivialidad o de la excesiva abstrac- ción, no las vuelve sospechosas de dogmatismo. Benhabib desarticula de manera satisfactoria la crítica que denuncia que las condiciones formales de la comunicación no son tan «minimalistas» como se proponen. En opinión de esta autora, la idea central de la ética comunicativa explica a la perfección por qué los presupuestos no son dogmáticos. Su reversibilidad dentro de la misma conversación moral los coloca al alcance de la argumentación y elimina la apariencia de circularidad de los mismos. Pese a ello no pueden quedar completamente suspendidos en la medida en que son reglas necesarias para que continúe la conversación moral. En palabras de Benhabib:

Los presupuestos de la conversación moral pueden cuestionarse dentro de la conversación misma, pero si quedan suspendidos o se infringen lo que sigue es la fuerza, la violencia, la coerción y la supresión. Así se evita la acusación de circularidad: al aceptar que los presupuestos de la conversación moral sean cuestionados dentro de la conversación misma, se los coloca al alcance de la argumentación. Pero, en la medida en que son reglas pragmáticas necesarias para hacer que continúe la conversación moral, sólo podemos ponerlas entre paréntesis para cuestionarlas pero no suspenderlas por completo. ${ }^{19}$

Por ende, a juicio de Benhabib esta reversibilidad que afecta al mismo contexto en que construimos las normas, se basa en la idea de que la desigualdad ha sido radicalmente cuestionada por la ética y la política modernas. Quien afirme, en cambio, que la desigualdad es admisible, deberá justificar argumentativamente su postura si no quiere ser llamado irracional. Pero, para que la desigualdad sea considerada racional esta tesis deberá alcanzar el asentimiento de aquellos a quien se dirige, lo cual es poco probable si las personas argumentan en ausencia de coerción. Benhabib llama la atención sobre la fragilidad de un punto de vista moral concebido al modo de la ética co- 
municativa, dado que nuestro mundo moral y político se distingue más bien por la lucha y la estrategia que por la conversación tendente al entendimiento. Sin embargo, para Benhabib la fragilidad de este punto de vista moral en un mundo en el que operan ampliamente las relaciones estratégicas no implica su irrelevancia. El filósofo como teórico social crítico se ocupa de desenmascarar los mecanismos estratégicos que envuelve la ideología política y la hegemonía cultural que viene unida a ella, con el fin de reforzar la tendencia hacia la universalidad y la imparcialidad del discurso político democrático - lo cual se traduce en una mayor sensibilidad e inclusión de todos los participantes-. En este sentido, señala Benhabib, la teoría discursiva no desarrolla un modelo positivo de instituciones en funcionamiento pero si un criterio normativo y crítico con el cual se pueden juzgar los arreglos existentes, en la medida en que estos suprimen el interés generalizable.

Un «universalismo interactivo» tal como lo concibe Benhabib, se sustenta en la reversibilidad de perspectivas y en la búsqueda de comprensión del punto de vista del otro. Este universalismo reconoce la pluralidad y las diferencias pero no las acepta como válidas «per se». En cambio, la diferencia es el punto de partida para la reflexión y la acción. Como ideal regulativo el universalismo no niega la pluralidad ni la existencia de identidades materializadas y concretas sino que busca incentivar la reconstrucción de un punto de vista aceptable por todos.

Benhabib expresa la congruencia del pluralismo de perspectivas enraízadas y concretas, con un punto de vista moral universalizable en su perspectiva del «otro generalizado» y el «otro concreto». El punto de vista del otro generalizado muestra precisamente este carácter universalista de la moral y la política, en tanto que «nos exige ver a todos los individuos como seres racionales con los mismos derechos y deberes que quisiéramos para nosotros mismos». Al tener en cuenta al «otro generalizado» «nos abstraemos de la individualidad y de la identidad concreta del otro». ${ }^{20}$ En cambio, el punto de vista del otro concreto muestra a cada ser racional como un sujeto «con una historia, una identidad y una constitución afectivo-emocional concreta». ${ }^{21} \mathrm{Al}$ centrarnos en este punto de vista dejamos aparte lo común entre nosotros y nos fijamos en la individualidad. Sin el «otro concreto» no es posible ninguna prueba de universalizabilidad porque carecemos de la información epistémica necesaria para juzgar la igualdad o la diferencia de nuestra perspectiva moral con respecto a la de los demás.

Con esta distinción Benhabib pretende corregir la inadmisible exclusión habermasiana de las cuestiones de la vida buena del ámbito de las cuestiones de justicia, o lo que es lo mismo la separación tajante entre la moralidad de la justicia y la moralidad del cuidado. Para la autora, el «otro generalizado» que representa la perspectiva de la justicia es al mismo tiempo un «otro concreto», en tanto que las categorías morales de «justicia, obligación y derecho, respeto, deber, valor y dignidad» expresadas en la primera perspectiva estarían vacías de contenido si no les adosamos las nociones de «responsabilidad, deseo de compartir, amor, cuidado, simpatía y solidaridad», recogidas en la segunda perspectiva.

Haciendo una comparación entre la ética comunicativa habermasiana y la posición original rawlsiana, Benhabib encuentra implausible la construcción de esta última como un proceso restringido de deliberación individual. En lugar de ello, debiéramos optar por un proceso con final abierto de argumentación moral 
intersubjetiva. Ambas concepciones son escenificaciones del ideal de imparcialidad que encierran acusadas diferencias. En primer lugar, según Benhabib, para la ética discursiva el punto de vista moral no debe pensarse como un proceso de razonamiento hipotético llevado a cabo por el agente o el filósofo moral, sino más bien como una situación de diálogo en que los agentes morales se comunican entre sí. En segundo lugar, a juicio de Benhabib, el modelo discursivo no impone restricciones epistémicas al razonamiento moral, tal como ocurre en la posición original, sino al contrario, cuanta más información posean los agentes morales sobre su sociedad y la situación e historia de los otros participantes más racional será su resultado. En tercer lugar, apunta Benhabib, al no haber restricciones de información tampoco hay asunto privilegiado de disputa moral. Los agentes morales no reflexionan solamente sobre los bienes primarios como en el caso de la posición original sino que cualquiera de sus consideraciones, deseos o intereses pueden ser objeto de disputa. Por último, los agentes morales también pueden cuestionar los presupuestos del propio diálogo, esto es, "pueden introducir metaconsideraciones acerca de las condiciones y condicionamientos bajo los que se realiza tal diálogo, así como evaluar su equidad», lo cual no es posible en la construcción rawlsiana, que presupone definitivamente fijada la equidad del procedimiento decisorio. ${ }^{22}$

\section{Conclusión}

A mi juicio, la idea de imparcialidad hecha explícita en la ética discursiva permite reinterpretar el lenguaje de los derechos a la luz de la consideración de nuestras necesidades actuales y también de las necesidades de los grupos desfa- vorecidos. Asimismo, el modelo discursivo da al traste con la distinción tajante entre justicia y vida buena, en la medida en que entiende como consideraciones de justicia aquellas que se refieren a las condiciones mínimas que posibilitan el desarrollo de todos los proyectos racionales de vida $\mathrm{y}$, por lo tanto, interpreta las trabas a este desarrollo como injusticias estructurales o como déficits en la realización efectiva de los derechos individuales.

Tal como expresé en el apartado II, para la propia Iris Marion Young existen dos valores universalistas de la vida buena, el primero, desarrollar y ejercer nuestras capacidades y expresar nuestra experiencia o autodesarrollo, y el segundo, participar en la determinación de nuestra acción y de las condiciones de nuestra acción, o autodeterminación. El violar estos valores de la vida buena nos introduce, a mi juicio, en el terreno de las cuestiones de justicia, porque estas violaciones constituyen impedimentos reales para el pleno ejercicio y desarrollo de los derechos de ciertos grupos de personas. Hablar en términos democráticos de estos derechos exige que también ellos puedan estar a nuestra disposición a la hora de debatir sobre las desigualdades fácticas todavía existentes. En este sentido, Benhabib expresa una opinión parecida:

Hablar de eliminar estos derechos del debate caracteriza mal la naturaleza del debate democrático en nuestras sociedades: si bien no podemos cambiar estos derechos sin procedimientos políticos y jurídicos extremadamente elaborados, siempre estamos debatiendo su significado, su alcance y jurisdicción. ${ }^{23}$

Desde mi perspectiva, la reflexión sobre la diferencia, sobre los «otros concretos» con una historia particular y enraizada, exige de nosotros un compromiso con la imparcialidad materializada en 
el punto de vista moral tal como lo articula la ética discursiva. Considerar seriamente los argumentos de los «otros concretos» nos obliga a trascender nuestro propio punto de vista para reflexionar sobre la validez del resto de perspectivas. Por ende, a mi juicio, la imparcialidad nos permite comprender por qué las voces de los «otros concretos» han sido silenciadas por el discurso moral y político dominante, al tiempo que nos acercamos al contenido de sus propuestas y reivindicaciones. Por último, el «universalismo interactivo» que propone Benhabib expresa de manera plenamente satisfactoria las ideas de reciprocidad, simetría, y reconocimiento mutuo que nos sirven como parámetros básicos de la discusión racional y que, paradójicamente, presuponen las teorías antiuniversalistas de la diferencia. La defensa de este universalismo débil se convierte en la condición de posibilidad de acceso a soluciones generalizables. Según mi criterio, el universalismo así concebido no es la expresión de una razón legisladora que deduce principios trascendentales de intemporal validez, tal como criticaba Young, sino la pauta regulativa necesaria para un proceso de conversación moral y político que se concibe como constante, reversible y nunca definitivamente cerrado. En suma, el universalismo procedimental inscrito en esta perspectiva, orienta nuestras interpretaciones sobre las instituciones justas y vertebra nuestras percepciones y críticas a la injusticia social.

He defendido que imparcialidad, universalismo y diferencia forman una constelación de elementos inseparables. A través de una versión comunicativadialógica de la justicia como imparcialidad, que he basado en las ideas de Jürgen Habermas y Sheyla Benhabib, he mos- trado que la inclusión de los grupos desfavorecidos en el entramado político democrático exige precisamente la democratización y la revitalización del espacio público con el fin de que tales grupos puedan traer a la arena política sus reivindicaciones legítimas. Esta revitalización exige una pauta normativa que sirva como marco de orientación para la argumentación entre las fuerzas políticas, la sociedad y los colectivos sociales. A mi juicio, la justicia como imparcialidad tal como la he descrito es la candidata idónea para ocupar este puesto. Sólo en un espacio público que posibilitara a los silenciados un medio para articular sus experiencias sería posible la progresiva normalización -que no asimilación- de las diferencias que tradicionalmente se han tenido por anómalas. $\mathrm{Si}$ elimináramos el escenario político en que este proyecto puede ser llevado a cabo a largo plazo, les robaríamos el arma más importante que quienes están en desventaja tienen para la consecución de una ciudadanía plena, o tal como señala Nancy Fraser, les impediríamos progresar en el logro de su «paridad participativa». Por lo mismo, frente a las críticas de los teóricos de la diferencia al universalismo y a la imparcialidad, considero imprescindible mantener una versión crítica de ambos conceptos en nuestro discurso político sobre la justicia. Los dos son imprescindibles para una correcta consideración de la diferencia, por cuanto sirven de pautas procedimentales para asegurar el respeto a todos los puntos de vista legítimos, el derecho a manifestarse a los excluidos y la posibilidad de conquistar la igualdad de oportunidades y derechos por parte de aquellos a quienes les han sido negados reiteradamente. 


\section{BIBLIOGRAFÍA}

Ackerman, B., Social Justice and the Liberal State, New Haven, Yale University Press, 1980.

Benhabib, S., Situating the Self, Cambridge, Polity Press, 1992. Edición original española: El ser y el otro en la ética contemporánea, Barcelona, Gedisa, 2006.

Dworkin, R., El imperio de la justicia, Barcelona, Gedisa, 1992.

Fraser, N., Scales of Justice: Reimagining Political Space in Globalizing World, Nueva York, Columbia University Press, 2010.

Fraser, N., «Feminist Politics in the Age of Recognition: A Two-Dimensional Approach to Gender Justice», en Studies in Social Justice, 1:1, 2007, 23-35. Traducción española: «La política feminista en la era del reconocimiento. Un enfoque bidimensional para la justicia de género», en Carbonero Gamundí, M. ${ }^{\mathrm{a}}$ Antonia y Valdivielso, Joaquín (eds.): Dilemas de la justicia en el siglo XXI. Género y globalización, Palma de Mallorca, UIB, 325-344.

Habermas, J., Teoría de la acción comunicativa I. Racionalidad de la acción y racionalización social, Madrid, Taurus, 2001.
Habermas, J., Verdad y justificación, Madrid, Trotta, 2002.

Honneth, A., The Struggle for Recognition, Reino Unido, Polity Press, 1995.

Honneth, A. y Fraser, N., ¿Redistribución o Reconocimiento?, Madrid, Morata, 2006.

Rawls, J., A Theory of Justice, Cambridge, Harvard University Press, 1971. Edición española: Teoría de la justicia, Madrid, FCE, 2002.

Rawls, J., Political Liberalism, Nueva York, Columbia University Press, 1993. Edición española: El liberalismo político, Barcelona, Crítica, 2006.

Sandel, M., Liberalism and the Limits of Justice, Nueva York, Cambridge University Press, 1982. Edición española: El liberalismo y los límites de la justicia, Barcelona, Gedisa, 2000.

Young, I. M., Inclusion and Democracy, Nueva York, Oxford University Press, 2002.

Young, I. M. «Polity and Group Difference: A Critique of the Ideal of Universal Citizenship» en Feminism and Political Theory, Chicago, The University of Chicago Press, 1994.

Young, I. M., Justice and the Politics of Difference, Princeton, Princeton University Press, 1990. Edición española: Young, I. M. La justicia y la política de la diferencia, Madrid, Cátedra, 2000.

\footnotetext{
1 El propio Rawls reconoce al inicio de El liberalismo político, el peso que tienen en su obra las cuestiones relativas a la tolerancia política y religiosa frente a otras relacionadas con la diferencia: «Podría parecer que mi énfasis en la Reforma y en la larga disputa acerca de la tolerancia como orígenes del liberalismo político resulta anacrónico a la vista de los problemas de la vida política contemporánea. Entre nuestros problemas más básicos están los raciales, étnicos y de género. Y podría parecer que éstos son
}

problemas de naturaleza muy distinta que requieren principios de justicia distintos de los discutidos por la Teoría». Rawls, J., El liberalismo político, Barcelona, Crítica, 2006, p.24 (edición original, Political Liberalism, Nueva York, Columbia University Press, 1993)

${ }^{2}$ Véase Young, I. M., Justice and the Politics of Difference, Princeton, Princeton University Press, 1990. Véase también Young, I. M. «Polity and Group Difference: A Critique of the Ideal of Universal Citizenship» en Feminism and Political Theory, Chicago, 
The University of Chicago Press, 1994, pp. 117-141. Young, I. M., Inclusion and Democracy, Nueva York, Oxford University Press, 2002.

3 Young, I. M. La justicia y la política de la diferencia, Madrid, Cátedra, 2000, p. 16.

${ }^{4}$ Otros autores que han criticado la reducción de los problemas de justicia a problemas de distribución. Entre ellos, uno de los más eminentes Axel Honneth plantea que la lucha por el reconocimiento es la más importante tarea que en nuestra actual democracia llevan a cabo los desfavorecidos y por lo mismo, la teoría política debería hacer hincapié en esta realidad. Véase, A. Honneth, The Struggle for Recognition, Reino Unido, Polity Press, 1995. Más recientemente, la filósofa Nancy Fraser ha insistido en la necesidad de tener en cuenta tres dimensiones de la justicia. En su discusión con Axel Honneth, Fraser habla de dos dimensiones de igual relevancia, la redistribución y el reconocimiento (Véase, Fraser, N., y Honneth, A., o ¿Redistribución o Reconocimiento?, Madrid, Morata, 2006). Más adelante, Fraser añadiría una tercera dimensión, la participación (Véase, por ejemplo, Scales of Justice Reimagining Political Space in Globalizing World, Nueva York, Columbia University Press, 2010).

5 Young, I. M., op. cit., 2000, p. 51.

${ }^{6}$ Young, I. M., op. cit., 2000, p. 67.

7 Young, I. M., op. cit., 2000, p. 116.

${ }^{8}$ En este punto la crítica de Young recuerda a la de los comunitaristas, aunque Young no se encuentra dentro de esta orientación filosófico-política. Véase, por ejemplo, Sandel, M., Liberalism and the Limits of Justice, Nueva York, Cambridge University Press,
1982 (Traducción española: El liberalismo y los límites de la justicia, Barcelona, Gedisa, 2000).

9 Young, I. M., op. cit., 2000, p. 167.

${ }^{10}$ Young, I. M., op. cit., 2000, p. 190.

11 Young, I. M., op. cit., 2000, p. 403.

${ }^{12}$ Habermas, J., Verdad y justificación, Madrid, Trotta, 2002, p. 292.

${ }^{13}$ Véase por ejemplo, Rawls J., El liberalismo político, op. cit.; Dworkin, R., El imperio de la justicia, Barcelona, Gedisa, 1992; Ackerman, B., Social Justice and the Liberal State, New Haven, Yale University Press, 1980.

14 Young, I. M., op. cit., 2000, pp. 159-160. Para otras referencias de Young a la teoría de Habermas, véanse por ejemplo, Young, op. cit., 2000, pp 18-19 y 61-62.

${ }^{15}$ Scanlon, T., What we Owe to Each Other, Cambridge, Harvard University Press, 1998 (Edición española: Lo que nos debemos los unos a los otros ¿qué significa ser moral?, Barcelona, Paidós, 2003).

16 Véase Habermas, J., Teoría de la acción comunicativa I. Racionalidad de la acción y racionalización social, Madrid, Taurus, 2001.

17 Benhabib, S., El ser y el otro en la ética contemporánea, Barcelona, Gedisa, 2006 p. 19 (Edición original: Situating the Self, Cambridge, Polity Press, 1992)

${ }_{18}$ Benhabib, S., op. cit., pp. 44-45.

${ }^{19}$ Benhabib, S., op. cit., p. 47.

${ }^{20}$ Benhabib, S., op. cit., p. 182.

${ }^{21}$ Benhabib, S., op. cit., p. 183.

${ }^{22}$ Benhabib, S., op. cit., p. 194.

23 Benhabib, op. cit., p. 125. 